\title{
Underground Cities : Sustainable Urbanism of the Future
}

\author{
Reshmi Manikoth Kollarath, Shanu Raina, Bhagyalaxmi Madapur
}

\begin{abstract}
Cities across the world are the main contributors to climate change but at the same time they are also the most vulnerable to its consequences. Some of the disastrous impacts of climate change include extreme weather events, periods of extreme heat and cold, high precipitation, floods, strong cyclones and storms. There is a need for urban design guidelines to effectively address the issues of climate chanbe and increase the resilience of cities. One way to adapt to this is through engineered infrastructure. Today nearly $70 \%$ of the world live in urban areas and in the next 20 years two billion more people are expected to move to the cities. With increasing urban densification land and buildable areas are going to become increasingly scarce. One possible solution is to build downwards instead of upwards. Underground areas are less susceptible to external influences and have the ability to better withstand natural catastrophes and hence can be sustainable solution for an unpredictable future. This paper will analyze the viability of underground cities through examples from history and existing case studies along with new upcoming proposals and probe how using underground spaces can increase the resilience of future cities.
\end{abstract}

Keywords-Climate change, urban underground spaces, underground cities, sustainability, urban resilience

\section{INTRODUCTION}

The world is today facing the consequences of uncontrolled urbanization, climate change and rapid resource depletion.According to United Nations Report $70 \%$ of world population will be living in urban areas by 2050 . By the turn of this century the urban population across the globe would also double.(UN, 2007,UN, 2013). Present day cities deal with problems ranging from traffic congestion, degraded environmental conditions because of pollution of air and water; breakdown of safety, security, and perils of natural disastersand flooding. Urban areas are overcrowded without space for recreation. Preservation of urban cultural heritage and aesthetics and repair and maintenance of old infrastructure for conveyance of water and sanitation are all major challenges facing our cities.[1] As the world faces an uncertain future fraught with dangers of rising sea levels and unpredictable weather patterns it becomes important to take steps to create resilient cities which can withstand these changes.

Underground cities are usually a series of subterranean spaces which can house shopping areas, transit centres and other such functions beneath the city. Underground Cities have existed historically. Underground spaces provide a constant climate throughout the year. As such these spaces will consume less energy for heating and cooling. The most crucial aspect in an underground city is to develop a system

Revised Manuscript Received on August 19, 2019.

ReshmiManikothKollarath,BMS College of Architecture, Bangalore, Karnataka, India (reshmimk@gmail.com)

ShanuRaina,BMS College of Architecture, Bangalore, Karnataka, India (raina.architect@gmail.com)

BhagyalaxmiMadapur,BMS College of Architecture, Bangalore, Karnataka, India (bhagyalaxmi.arch@bmsce.ac.in) of self propelling air conditioning. This is achieved through ventilation shafts which allow air to circulate itself.

Some of the benefits of underground cities are

1. Safety considerations - In current circumstances against nuclear or bombing attacks.

2. Reducing occupation of surface areas

3. Reducing need for heating and cooling energy.

4. Reducing noise pollution

5. Reducing dust loads

6. Reducing environmental load

7. Reduces demand on transportation

8. Reduces travel time.

9. Helps to preserve existing, historical, cultural, architectural values and buildings.[2]

\section{UNDERGROUND CITIES IN HISTORY}

There are many historical examples of people living underground. Such settlements were usually found in places with extreme heat or cold. In some cases these cities mainly served as spaces for defense purposes. Most of these cities contain spaces found in other cities such as religious spaces, spaces for communal gatherings, bedrooms, kitchens, bathrooms, spaces for animals, water tanks, storage areas, tombs etc. But they also contain certain spaces which are very specific to them such as ventilation shafts and connecting tunnels. [2]

\section{A. Derinkuyu}

Derinkuyu is located in Cappadocia , Turkey along with 40 other underground sites. Derinkuyu could accommodate around 20,000 people and was continuously occupied from the $8^{\text {th }}$ century BCE to as late as 1923 .

Derinkuyu went down to a depth of $60 \mathrm{~ms}$ underground and it contains oil presses, cellars, stables, chapels and store rooms.

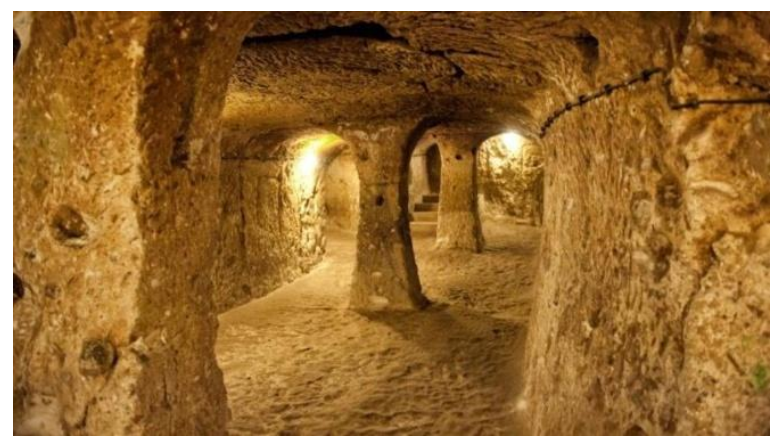

Fig 1. Derinkuyu, Turkey

Source:www.history.com

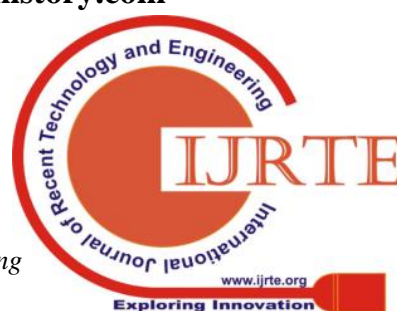




\section{B. PilsenHistorical Underground, Czech Republic}

Pilsen's underground has $20 \mathrm{~km}$ network ofpassageways and cryptsthat go through the heart of the city. The underground hascorridors, cellars and wells. The construction of Pilsen'shistorical underground started in the 13th century and continued up to the 19th century. The Underground is comprised of two or three level cellars. The space was used for food preservation, manufacturing, for malt-houses and also as wine-vaults. These passageways also acted as galleries conveying water to the water supply tower and also served the purpose of sewage and wells. In the front lot are the oldest houses while the back-yards were used as stables, sheds and wells. Dry wells were utilized as dumping grounds.

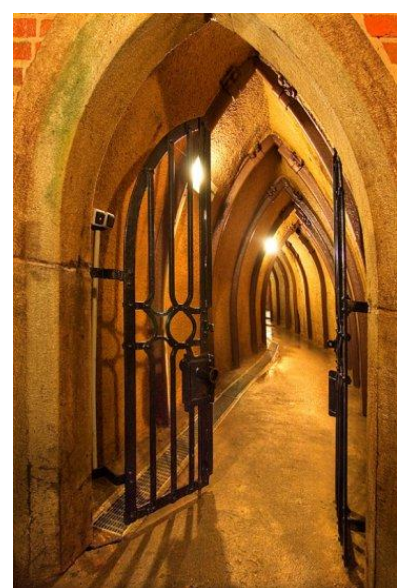

Fig 2. Pilsen Historic Underground Source:inyourpocket.com

\section{B. Naours, France}

Naours is situated in northern France and more than 3 $\mathrm{kms}$ of underground passageways and 300 rooms. The underground network is located $30 \mathrm{~ms}$ below a forested plateau. The area was a Roman limestone quarry since the $3^{\text {rd }}$ century. It became an underground village when the locals started using it for hiding during the medieval period. This underground network could hold a population of 3000 and contained spaces for worship and for animals, wells and bake houses.

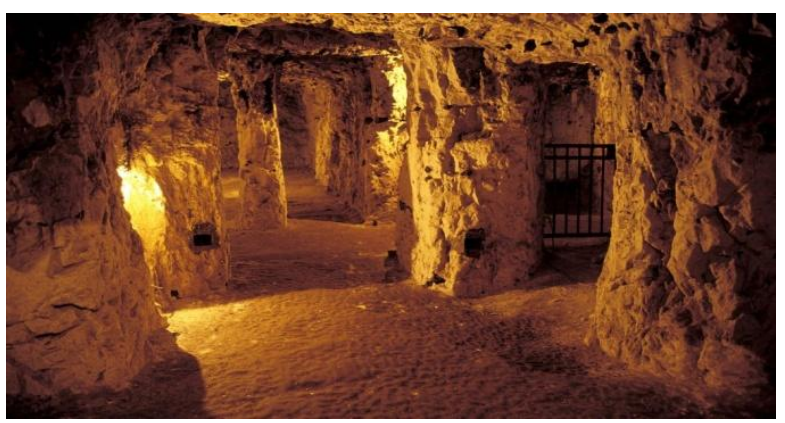

Fig 3. Naours Underground City Source:michelintravels.com

\section{Underground cities - present scenario}

Urban Underground Spaces (UUS) have grown significantly in the world's wealthiest cities in the past decade. With instances of extreme weather conditions on the rise across the world along with pressure of increasing population and limited land resources there are many futuristic subterranean spaces being planned across the world.

\section{A. Helsinki Underground City}

The Helsinki Underground master Plan was approved by the city council in 2010. The Helsinki Underground City has metro stations, six storey shopping areas, churches, swimming pools etc. The subterranean city houses a data centrewhich isuses the water from sea for cooling instead of electricity. The heat generated is then conveyed through pipes to be used for household utilization. This underground has 200 kms of tunnels.

The Underground City will increase the natural insulating property of the bedrock to reduce energy demand during extreme cold conditions. Many of the spaces are carved into the bedrock creating an architectural marvel. In the coming years the Underground planwill be used for constructing 200 subterranean structures which will comprise both metro lines as well as road networkswhich will connect to the transportation network of the existing over ground city.

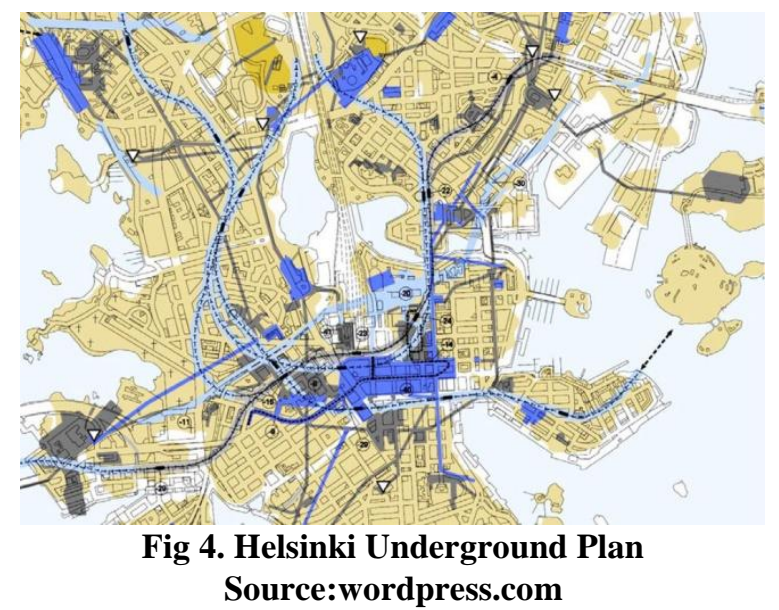

\section{B. Reso, Montreal}

Reso in Montreal is the biggest underground structure in the world with the largest pedestrian network. This network is distributed over an area of 12 square kilometers and is more than $32 \mathrm{kms}$ long. The entire complex is situated below the streets of Montreal. The development of this underground complex started in the 1960s and consists of mainly residential and commercial spaces. This underground city consists of many levels and includes shopping complexes, cinemas, banks, hotels, metro stations, theatres, galleries, nightclubs, university buildings, restaurants, a library and a hockey rink.

The underground city is mainly a shopping haven and is not used for residential purposes. 


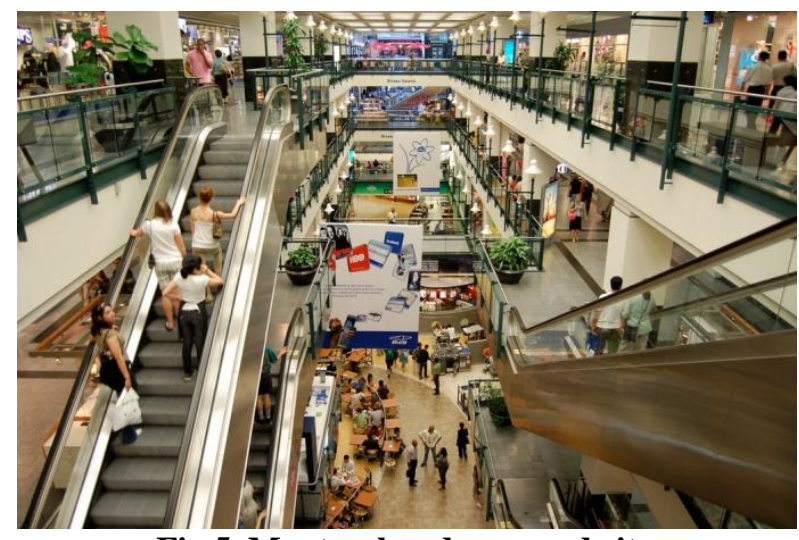

Fig 5. Montreal underground city

Source:http://gomontrealtourism.com/5-things-know-montrealsunderground-city/

\section{Singapore Underground Master Plan}

Singapore is estimating a population growth of 6.9 million by 2030. This small island nation has a severe shortage of land resource in face of increasing population. So the country is exploring its underground. Singapore has the greatest district cooling system underground in the world, a conservation system for reclaiming water as well as weapon storage for Singapore Armed Forces. It is also increasing its underground railway network by adding another $180 \mathrm{kms}$ by 2030 .

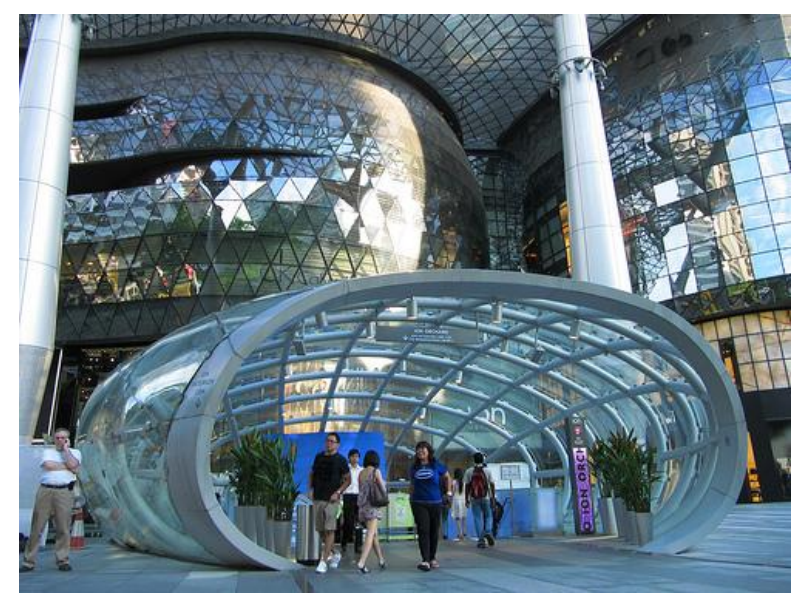

Fig 7. Entrance to MRT and subterranean shopping space in Orchard Road Source:flickriver.com

Singapore Underground has been planned in many layers. i) $\mathbf{1 m - 3 m}$

Pedestrian Links to connect between buildings and to cross busy streets.

\section{ii) $1 \mathrm{~m}-10 \mathrm{~m}$}

Common services Tunnel

\section{iii) $15 \mathrm{~m}-\mathbf{5 0 m}$}

Major road and railway networks cutting through already built up areas cutting down noise and pollution.

iv) $20 \mathrm{~m}-\mathbf{5 0 m}$

Deep tunnel Sewerage system that carries waste water to the reclamation plants.

\section{v) $\mathbf{1 0 0} \mathrm{m}$ onwards}

Underground ammunition facility to store ammunition and explosives.
Singapore will be launching its underground plan in 2019.[3]

\section{UNDERGROUND CITIES - NEW INITIATIVES \& RESULTS}

\section{A. Lowline, New York}

Lowline in Manhattan is an ongoing initiative aimed at converting abandoned 1 acre trolley terminal into a park using 'remote skylight technology'. This technology uses receptors which are located above the ground. These receptorscaptures sunlight which is then channeled underground where it is dispersed. This natural sunlight then allows a variety of plants, vegetables and fruits to grow. This project is currently mobilizing funds and has also inspired other cities such as Paris, Seoul and Moscow to build subterranean parks spaces.

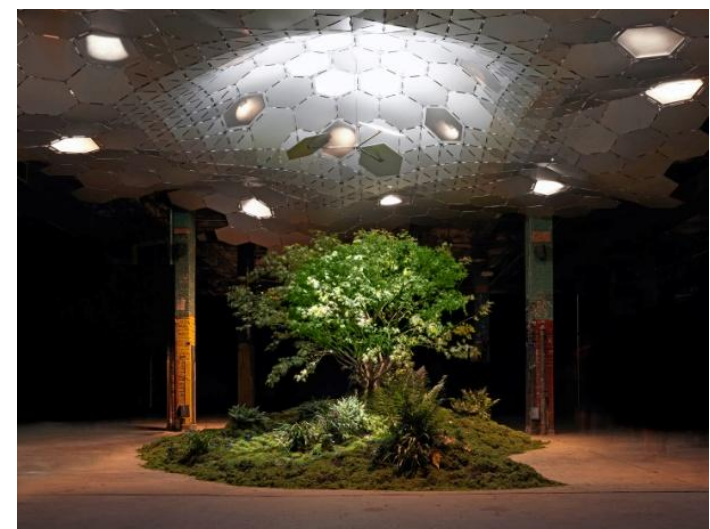

Fig 6. Lowline, New York

Source:cameronmeilson.com

\section{B. Earthscraper, Mexico City}

The Earthscraper is gigantic inverted pyramid which will also be the world's largest underground city which will contain a population of 100,000 . This pyramid will be constructed beneath Zocalo, the main square of Mexico City.

Zocalo is the historic core of Mexico City. The Colonial city here was built above the pyramids of an Aztec city. The historic center has many protected heritage buildings and a height restriction which prohibits building up.so the only solution was to build down.

Earthscraper goes down to a depth of $300 \mathrm{~ms}$. The underground floors avail natural light through a glass roofwhich is further augmented by fibre optics lighting. The ' Earth Lobby' present at every ten floors consists of vertical gardens which provide both fresh air as well as food. Museums and art galleries will occupy the first ten floors, while the next ten floors beneath contains commercial and residential spaces. The lowermost floors will be reserved for offices and other uses.

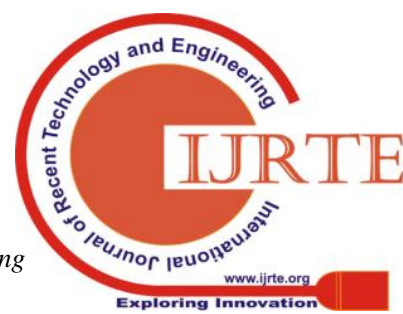




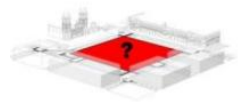

1

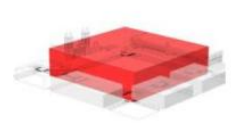

4

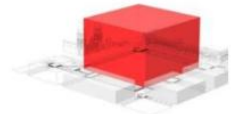

2

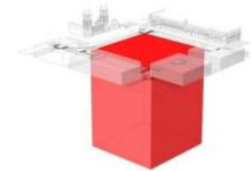

5

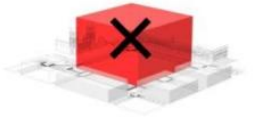

3

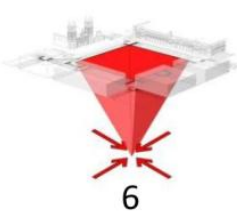

Fig 7. Earthscraper, Mexico city

Source:http://www.descroll.com/architecture/the-earthscraper-bybnkr-arquitectura

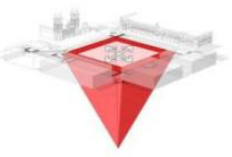

The Transparent Glass Roof
Source:http://www.descroll.com/architecture/the-earthscraper-bybnkr-arquitectura

The subterranean structure preserves the iconic presence of the city square and the prevailing echelons of the historic structures around it. This inverted pyramid allows all spaces underneath to utilize natural light as well as ventilation with the help of the central open space which is created.In order to maintain the various activities such as concerts, political manifestations, open-air exhibitions, cultural gatherings, military parades etc which happen throughout the year the gigantic central space will have a glass ceilingwhich will connect the Earthscraper with the day to day happenings on the city square visually.[4]

A double structural envelope has been designed to support the floor loads and retain the surrounding subsoil. The exterior barrier wall is not only the retaining structural membrane but also conveyor of infrastructure. Turbines in the lower floor will pump clean water through the membranes to every floor.The gray water will come down and be treated and reused for irrigation.Electricity will be generated through the working of turbines.

Earthscraperwill be a new kind of landmark in the city , both invisible and monumental.

\section{CONCLUSION}

Underground Cities could very well become a norm in the future with already many structures being built underground. Even though scarcity of surface area in cities will become the drivers for such spaces it doesn't necessarily mean that the need for these surface spaces would decrease in future. On the other hand as the underground city will grow it will start exerting more pressure above ground as well. All underground cities will require to have services above ground for light, ventilation and other resources.
The main constraint for living underground is light. But with innovations in fibre optics and innovative techniques such as 'remote skylight technology', it is possible to live underground.

Underground development can be a significant strategy for evolving urban areas to meet the challenges of the future. Underground Spaces are better placed to meet natural disasters especially earthquakes and seismic activity. By placing infrastructure facilities underground culturally rich heritage urban areas can be preserved. The use of urban underground spaces also reduces the environmental impact on the cities. These benefits can be incorporated in the newly planned cities with even more cost effectiveness than in existing cities. It is important that urban planners and designers recognize the potential of the underground and use it effectively during city planning.

\section{REFERENCES}

1. Broer, "Urban Underground Space: Solving the Problems of Today's Cities", Tunneling and Underground Space Technology, May 2016, p245-248

2. Nyvlt et al,“" The Study of Derinkuyu Underground City in Cappadocia Located in Pyroclastic Rock Materials". Procedia Engineering, 2016, p2253-2258

3. https://citi.io/2017/10/09/the-secret-underground-world-ofsingapore/.Retrieved in March 2019.

4. http://www.descroll.com/architecture/the-earthscraper-bybnkr-arquitectura Retrieved in March 2019. 